\title{
Methods and Strategies for Interaction between Teaching and Teaching Research
}

\author{
Yueshan Fang \\ Yanbian University, Yanji, 133002, China
}

Keywords: Teaching, Teaching research, Interaction

\begin{abstract}
Teaching and teaching research play a vital role in educational work. Theories, problems and phenomena occurring in the teaching process are studied and discussed and research results are determined. Meanwhile, such results are applied to teaching practice. Therefore, teaching and teaching research rely on, influence and restrict each other. It is most important to achieve the interaction between teaching and teaching research in the educational work of each school. Only with interaction can they realize their value and significance.
\end{abstract}

\section{Introduction}

Teaching is a talent training activity in which teachers guide students in learning scientific and cultural knowledge and skills in a planned and organized way. Teaching research is a process of study under the background of teaching knowledge and application to teaching. Therefore, teaching and teaching research are interactive and continuous. Without teaching, teaching research cannot be conducted actually. Without teaching research, teaching cannot be regarded as teaching in the real sense. However, there are great differences in the realization of interaction between teaching and teaching research in the current process of educational work. This paper puts forward methods and strategies for the interaction between teaching and teaching research in several aspects in allusion to the status quo of teaching and teaching research.

\section{Status quo of teaching research}

\section{Weak awareness of teaching research workers about research}

Many teaching research workers cannot understand the form of teaching research work and specific research work. Ideas of relevant school departments and teachers influence the interaction between teaching and teaching research. Teaching workers lack relevant research awareness and pursue for teaching level, teaching theories and the completion of teaching objectives blindly in terms of teaching research work. They are not enthusiastic about teaching research projects. Therefore, teaching research workers lack certain self-awareness in teaching research and make teaching research work stand still ${ }^{[1]}$. Teaching workers in some institutions publish in-depth views on teaching research on relevant publications. Meanwhile, many in-depth teaching research reports are listed on authoritative periodicals. Schools only display them in the library and fail to encourage, support and guide teaching workers.

\section{Limitation of teaching research direction}

Teaching researchers mainly study educational issues, while education involves subject education, experimental education and issue education etc. For educational workers, research direction is limited due to the extremely strong disciplinarity. For example, it is very difficult for teachers learning literature to study relevant issues of physics. However, disciplinary teaching researches are generally conducted by relevant disciplinary researchers. In addition, teaching researchers should study other fields based on relevant experience. For example, issues about students' examination involved in education, school management work and the communication among students, parents and 
teachers can be studied deeply. therefore, teaching research direction should not be limited to a single one. Explorations should be made in multiple directions.

\section{Restricted teaching conditions of schools}

We know that teaching research requires certain manpower, material resources and financial resources. Teaching research work can be implemented more smoothly only under certain conditions. However, Chinese teaching workers are not in the same level. Rural teaching conditions are limited ${ }^{[2]}$. First, it is very difficult to run a school. Attention is mainly focused on students' teaching work. It is not key to consolidate and improve teaching research, let alone study teaching and promote teaching work. Second, there is no opportunity for learning, exchange and practice in teaching research work. For example, remoter mountainous schools have poorer conditions. All value of teaching workers is theoretical study of each student. The interaction between teaching and teaching research is limited. Relevant instruments and equipment are incomplete, let alone meet teaching research objectives under modern new curriculum standard. In schools with superior conditions, all manpower and energy might be put on students' entrance to a higher school and examination. Such schools emphasize educational outcomes and teaching workers do not have spare time for studying relevant subjects and educational concepts. Practice only aims at meeting the demand of teaching subject and teaching research only aims at promotion. Various factors cause the failure to implement research work comprehensively.

\section{State of mutual independence of institutions}

Currently, teaching and teaching research are independent from each other and do not influence each other in most institutions. In institutions with common teaching conditions, teaching and teaching research are in a low level and scientific research achievements cannot keep pace. Meanwhile, their thinking is narrow and cannot meet teaching changes and the need of social economic development. However, institutions with better teaching conditions focus on teaching practice rather than interaction between teaching and teaching research and teaching and teaching research are independent from each other. Meanwhile, good theoretical achievements cannot be applied to teaching appropriately. Therefore, teaching research achievements cannot be communicated and exchanged among institutions. Teaching research cannot be communicated among institutions in time.

\section{Attention not paid to practical link}

Teaching research work must be based on practical theory. Separated from practice, teaching research work will be unconvincing. Therefore, teaching and teaching research work must interact in practical link ${ }^{[3]}$. Under new curriculum standard, various emerging scientific and technological products are applied to teaching work and teaching work is no longer limited to books. The occurrence of internet has changed teaching and realized teaching interaction. For example, many disciplinary experiments cannot be analyzed comprehensively in the teaching process, but can be presented comprehensively through computer picture, dynamic video, professional sound and visual experience so as to guide practical operation, achieve the original teaching objective and then provide certain practical help for teaching research work.

\section{Strategies for interaction between teaching and teaching research}

Feasible strategies should be put forward in the teaching and research process so that teaching and teaching research are interactive in operation. Teaching should be consistent with teaching research objectives. It is required to make them integrated with each other, realize their maximum value and define the direction of teaching practice. Teaching work provides theoretical basis for students and serves teaching research. Meanwhile, teaching research acts on teaching work. Feasible strategies are put forward for their organic integration below. 


\section{Improve awareness of educational workers about teaching research}

Undoubtedly, educational workers staying in the frontline of teaching are more suitable for teaching research. Their mastery of ideological culture and experience of teaching skills determine that they are more suitable for being researchers. Therefore, it is urgent to improve the awareness of educational workers about teaching research in allusion to their weak awareness about teaching research and lack of initiative and enthusiasm.

Currently, Chinese educational workers are mainly engaged in teaching work and study teaching contents. They mainly use foreign advanced experience or mature teaching concepts. In terms of teacher training, schools mainly focus on their theoretical level and practical teaching and their ability of driving students' expressive force in class. The lack of training on teaching research and strengthening of teaching research awareness makes their teaching practice foundation only stay at students' classroom teaching and causes the failure of profound comprehension and practice in teaching research. Therefore, schools play a vital role in the improvement of teachers' ability of teaching research. On the one hand, schools should seek for new methods for teacher training mode. They should not simply impart teaching theories, but also constantly improve teachers' interest in educational work and teaching theories and allow them to conduct investigations in practice, stimulate their power of studying educational work, care about current educational situation and concepts, give opinions on educational problems, combine facts with the reality, learn educational knowledge, improve research ability and strengthen the awareness of research ${ }^{[4]}$. On the other hand, teaching researchers should combine theories with reality and make practice serve teaching contents so as to achieve guiding research results for younger generations. In China, current research achievements of educational theory are inconsistent with most teaching practice. Strongly disciplinary theoretical achievements have been made without specific operational process. Such impractical issues do not have reference value for teaching work and will influence the next teaching research. Therefore, teaching researchers must have research awareness and be engaged in both teaching and teaching research so as to achieve the maximum value of teaching.

\section{Combine teaching and practice}

Teaching and practice should combine with each other so as to achieve maximum unification. The teaching process mainly relies on theoretical knowledge. Practice comes from the external society. For example, "the birth and circulation of newspaper" are mainly taught in school teaching. Students only see simple newspaper. Manuscripts are arranged on the page with relevant software, thus presenting the effect of a picture. However, they don't know how complicated those steps experienced by the circulation of this newspaper are. If only theoretical knowledge is imparted simply, students can only acquire theoretical basis and teachers are only limited to teaching contents. However, if some professional personnel staying in the frontline of newspaper circulation are invited for explaining the process of birth, circulation and distribution of newspaper and students can visit a printing house practically and experience the process of newspaper composing and circulation in person in combination with news gathering and editing and manuscript writing, they can master the foundation of teaching profoundly. Meanwhile, students can master new knowledge and combine theories with practice in this process. Teachers can make knowledgeable achievements in research. Moreover, professional theory explanation is also very important. Experts with profound understandings in the industry can be invited. They can give more profound opinions on teaching research from the perspective of researchers. Such profound opinions cannot be obtained by teaching workers from teaching work. Therefore, only with scientific training program, guidance of professionals and combination of theory and practice can operable practical teaching be achieved.

\section{Accumulate excellent teaching research achievements}

In recent years, due to non-significant achievements of teaching research and theses of educational workers of varying quality, institutions have started to attach importance to teaching research and set about conducting teaching research. It is required to specify their talent training objectives and 
training mode, pay attention to the combination of theory and practice and master certain professional skills; set up educational and teaching concepts, center on students, focus on solving problems, promote learning methods with teaching methods and then establish an integrated structure of theory and experiment; apply flexible teaching methods, change teaching in traditional mode, adopt interactive teaching pattern, obtain the integration of emotion and knowledge in discussions and exchange, intensify the consciousness of question and improve the ability of solving problems. Teaching research theses are not engaged in idle theorizing; instead, they have profound reference value. Therefore, teaching workers can discover some development rules of teaching and then accumulate excellent teaching research achievements through the mastery of some teaching achievements, mode and contents over the years. These research theories will be better applied to their research category as well as teaching contents, thus causing reform ${ }^{[5]}$.

\section{Try to use new teaching methods}

Under the situation of reform of new curriculum standard, teaching mode no longer copies the original one or adheres to the obsolete teaching system. Instead, it is required to change teaching methods innovatively and flexibly under the premise of new economy and era so as to be adapted to the varying social development environment. In traditional teaching, teachers impart academic knowledge and students accept theoretical knowledge gained in class. All theoretical knowledge should be absorbed and consolidated by students. They are unable to exchange such knowledge. Educational talents trained under such mode are restricted in educational concept and thinking innovation. Therefore, it is required to have varying teaching methods and introduce interactive, discussion and open teaching to teaching practice under the current new situation. Teaching workers can enter the class with questions, ask students questions in a specific scene, initiate a discussion for meeting of minds, encourage students to express their opinions boldly, satisfy students' desire of being a teacher, exchange the role with students and impel students to think deeply and participate in classroom learning more comprehensively and effectively. Therefore, good teaching methods should be learnt and adopted flexibly. Only with appropriate teaching methods can the foundation of teaching research workers be improved and their awareness of interaction be strengthened. It will be of great advantage for next teaching research work.

\section{Conclusion}

Teaching does not simply refer to knowledge impartial and problem solving. More importantly, it should be research project in educational work. Teaching is the core of teaching research and teaching research cannot be separated from practical exploration. This is the principle of combination between theory and practice. The interaction between teaching and teaching research just realizes mutual unification between theory and practice. Only by experiencing and studying teaching deeply and discovering advantages and disadvantages of teaching can a teaching researcher summarize and explore common problems and rules of teaching, use them for guiding and demonstrating teaching research, drive teaching in each aspect and promote the reform in educational circle. Today with rapid economic development, methods for the interaction between teaching and teaching research are not changeless. This requires educational workers to adapt themselves to environmental and social development trend in the specific teaching work. Teaching cannot be limited to theory. Instead, it should advance with the times and be adapted to economic development. Meanwhile, it is necessary to adjust objectives and direction of teaching research constantly, apply new research achievements to theoretical teaching and make it more flexible and practical.

\section{Acknowledgments}

This paper is a teaching science fund program of Jilin Province, No. GH12028. 


\section{References}

[1] Wang Saili. Effectiveness of Establishment of Teaching Research Platform for Improving Interaction between Teachers and Students in Collective Teaching. Education Science and Culture Magazine, 2012(3):77-78.

[2] Chen Dongmei. Interaction between Teaching Research and Teaching. Exam Weekly, 2013(85):170-171.

[3] Li Jiemei. Promote Construction of Research-based Teaching System with Teaching-Research Interaction and Teaching-Management Combination - Thinking Based on "Academic Week" Activity of Wuhan Institute of Technology. Leadership Science Forum, 2015(1):42-43.

[4] Ruan Xiaolei. Implementation of Establishment of Micro-teaching and Research Interactive Platform for Promoting Effective Teaching. Reading, Writing and Arithmetic (Teaching and Research Edition), 2014(2):199-199.

[5] Zhang Dejiang. "Two Interactions" Required in Construction of Excellent Course. Management Observer, 2010(1):19. 